\title{
Impedance Synthesis Based Vibration Analysis of Geared Transmission System
}

\author{
Yafeng Ren, ${ }^{1}$ Shan Chang, ${ }^{1}$ Geng Liu, ${ }^{1}$ Liyan Wu, ${ }^{1}$ and Teik C. Lim ${ }^{2}$ \\ ${ }^{1}$ Shaanxi Engineering Laboratory for Transmissions and Controls, Northwestern Polytechnical University, Xi'an 710072, China \\ ${ }^{2}$ College of Engineering and Applied Science, University of Cincinnati, Cincinnati, OH 45221, USA \\ Correspondence should be addressed to Geng Liu; npuliug@nwpu.edu.cn
}

Received 6 January 2017; Revised 2 April 2017; Accepted 12 April 2017; Published 20 June 2017

Academic Editor: Jeong-Hoi Koo

Copyright (c) 2017 Yafeng Ren et al. This is an open access article distributed under the Creative Commons Attribution License, which permits unrestricted use, distribution, and reproduction in any medium, provided the original work is properly cited.

\begin{abstract}
The severity of gear noise response depends on the sensitivity of geared rotor system dynamics to the transmission error. As gearbox design trending towards lighter weight and lower noise, the influence of housing compliance on system dynamic characteristics cannot be ignored. In this study, a gear-shaft-bearing-housing coupled impedance model is proposed to account for the effect of housing compliance on the vibration of geared transmission system. This proposed dynamic model offers convenient modeling, efficient computing, and ability to combine computed parameters with experimental ones. The numerical simulations on system dynamic characteristics are performed for both a rigid housing configuration and a flexible one. Natural frequencies, dynamic mesh forces, and dynamic bearing reaction loads are computed, and the housing compliance contribution on system dynamic characteristics is analyzed. Results show that increasing housing compliance will decrease the system natural frequencies and will affect the dynamic bearing reaction loads significantly but have very little influence on the dynamic mesh force. Also, the analysis shows that bearing stiffness has significant influence on the degree of housing contribution on system dynamic characteristics.
\end{abstract}

\section{Introduction}

Due to the time-varying mesh stiffness and manufacture error of gear teeth, geared transmission systems will inevitably induce unwanted vibration and noise. The key to predict system dynamic characteristics reasonably is to take into account influences of all main mechanical components. As an important component of a gearbox, the housing not only plays an important role in the vibration propagation and noise radiation but also affects system dynamic characteristics significantly, especially in geared transmissions of helicopters, marine vessels, and automobiles.

A simple way to analyze geared transmission system vibration and noise responses is to apply a lumped parameter model to calculate the bearing reaction loads [1-3]. A more sophisticated approach is to construct a finite element (FE)/boundary element (BE) model of gearbox housing and apply the bearing reaction loads to the housing as forced excitation to simulate structure-borne and air-borne noise responses $[4,5]$. However, in most research efforts, the housing dynamics is frequently ignored and bearings are considered to be directly connected to a rigid foundation when calculating the bearing reaction loads. As these models neglect the housing compliance, they may differ from the practical case. With the gearbox design trending towards lighter weight and lower noise, the influence of housing on gearbox vibration and noise becomes more pronounced.

Dynamic modeling methods that are able to take into account the housing compliance include finite element method (FEM) [6-8], static substructure synthesis method (often referred to as simply substructure synthesis method) $[9,10]$, multibody dynamic modeling method [11], substructural modal synthesis method (often referred to as dynamic substructural synthesis method) [12], and substructural mobility synthesis method $[13,14]$. Lim and Singh [15] reviewed the overall gearbox dynamics and discussed the major modeling challenges. Rigaud and Sabot [16] reported that natural frequency and modal shape both changed when geared transmission system is coupled with housing. Hambric et al. [6] 
built a finite element model to investigate the influence of housing on the modal shape of shaft. Choy et al. [17] concluded that the influence of housing on system vibration is more pronounced in a stiffer rotor. Liu et al. [11] reported that housing compliance will deteriorate bearing vibration, but $\mathrm{He}$ et al. [9] showed that housing compliance will decrease vibration of both gear and bearing. Parker et al. $[8,18]$ established both a finite element model and a lumped parameter model and concluded that housing has limited influence on the gear dynamic transmission error but can play an important role on the bearing reaction load fluctuation and noise radiation. Abbes et al. [12] investigated vibration response of the housing and showed that housing vibration will be reduced when a stretcher is applied. Hajžman and Zeman [19] and Zhu et al. [7] also studied the housing vibration and noise in a coupled geared transmission-housing model. Jauregui et al. [20] estimated the influence of housing stiffness on the synchronization of nonlinear elements in a wind turbine gearbox. Rook and Singh [13] suggested that increasing housing stiffness, gear damping, shaft damping, or bearing damping will reduce vibration and noise. Leung and Pinnington [14] pointed out that the vibratory energy transmitted to the housing by gear tangential excitation force is much bigger than that excited by gear normal excitation force. Zhang et al. [21] evaluated the coupling loss factor between plate and gear shaft and concluded that symmetric layout reduces housing vibration. Gao et al. [22] demonstrated that high frequency vibration energy induced by torque fluctuation attenuates substantially after being transmitted through the gear-shaft-bearing path.

When the housing geometry is too complex to construct from a solid model, or too complex for finite element analysis, experimental setup has to be applied to extract the relevant parameters. For example, the geometrical design of a marine gearbox with a flexible housing, isolators, and a foundation is often very complex. Most of the previous studies applying the methods described above did not make use of the measured data directly. The impedance synthesis approach is an effective way to combine theoretical parameter with experimental ones and has been widely used in the past $[23,24]$. However, this method is seldom applied in the dynamic analysis of the coupled gearbox housing and internal geared transmission. This study attempts to address these gaps.

In this study, a coupled gear-shaft-bearing-housing model is proposed based on the impedance synthesis approach. This proposed approach only needs independent modeling of each subsystem and combines their impedances at their interfacial connections instead of directly representing the entire system in a single model. The gear, shaft, and bearing impedances can be derived from a lumped parameter model, and the housing impedance can be obtained from either a finite element (FE) model or an appropriate experimental setup. The proposed modeling is convenient to implement and computationally efficient. System dynamic characteristics are computed for both a rigid housing configuration and a flexible one using this method, and the influence of housing impedance on dynamic characteristics of geared transmission system is studied.

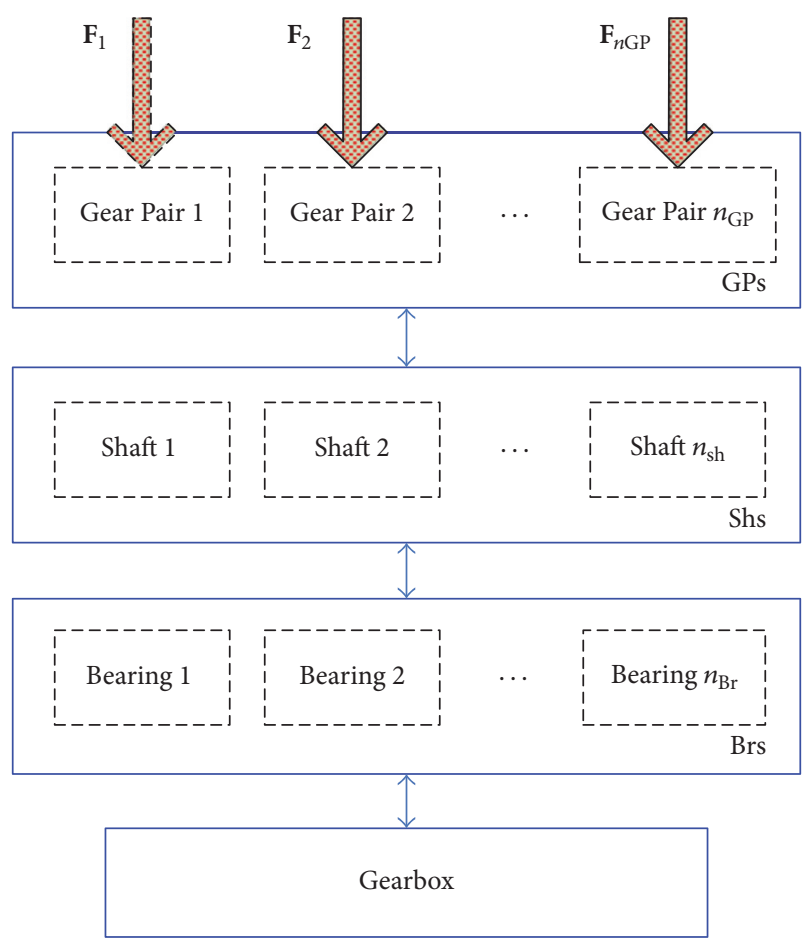

FIGURE 1: Schematic of a typical gearbox structure.

TABLE 1: Basic gear parameters.

\begin{tabular}{lcccc}
\hline $\begin{array}{l}\text { Tooth } \\
\text { number }\end{array}$ & $\begin{array}{l}\text { Normal } \\
\text { module }\end{array}$ & $\begin{array}{c}\text { Pressure } \\
\text { angle }\end{array}$ & $\begin{array}{c}\text { Helix } \\
\text { angle }\end{array}$ & $\begin{array}{c}\text { Face } \\
\text { width }\end{array}$ \\
\hline $24 / 79$ & $3 \mathrm{~mm}$ & $20^{\circ}$ & $15.09^{\circ}$ & $45 \mathrm{~mm}$ \\
\hline
\end{tabular}

\section{Subsystem Impedance}

Composition of a typical gearbox structure is shown in Figure 1. Gears are mounted on shafts, and gears-shafts are coupled to the housing through bearings. Conventional lumped parameter models assume bearings to be directly mounted on a rigid foundation and hence ignored the effect of gearbox housing on the system dynamic characteristics. In this study, housing compliance will be taken into consideration by coupling the entire gearbox into a single system. To absorb vibrations, the gear housing is sometimes mounted on isolators. Though isolators are ignored here, they can be modeled in the same way like the housing.

Geared transmission error excitation is applied on the gear system, while other force and moment fluctuations are ignored. Housing deformation or shaft assembly error may lead to nonparallel gearing condition and thus influences the mesh stiffness [25]. However, in order to simplify the problem, this factor is ignored and will be studied in the future.

The studied gearbox with a transmission system and housing is shown in Figure 2. The transmission system contains a helical gear pair, two shafts, and four bearings. Rotational speed of the input shaft is $1000 \mathrm{rev} / \mathrm{min}$, and driven torque of the output shaft is $1200 \mathrm{~N} \cdot \mathrm{m}$. Basic gear parameters are tabulated in Table 1. Parabolic profile modification is 
TABLE 2: Shaft segments dimensions (mm).

\begin{tabular}{lccccccc}
\hline & Number 1 & Number 2 & Number 3 & Number 4 & Number 5 & Number 6 & Number 7 \\
\hline $\mathrm{OD}_{1}$ & 30 & 38 & 40 & 48 & 48 & 45 & 48 \\
$L_{1}$ & 50 & 62 & 18 & 41 & 58 & 41 & 18 \\
$\mathrm{OD}_{2}$ & 55 & 63 & 65 & 45 & 62 & 52 & 55 \\
$L_{2}$ & 21 & 29 & 12 & 45 & 55 \\
\hline
\end{tabular}

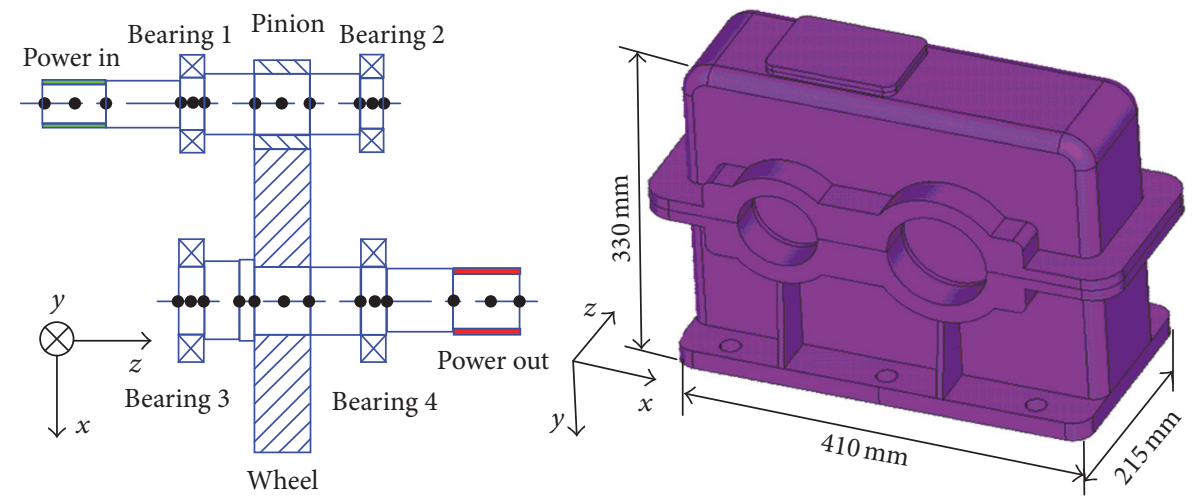

Figure 2: Gearbox layout design.

adopted. Tip relief is applied on both the pinion and the wheel, the length of profile modification is $7 \mathrm{~mm}$, and the amount of profile modification is $15 \mu \mathrm{m}$. Shaft dimensions are tabulated in Table 2. The housing is made of aluminum alloy and the length $\times$ width $\times$ height is $410 \mathrm{~mm} \times 215 \mathrm{~mm} \times$ $330 \mathrm{~mm}$, respectively.

2.1. Gear Pair Impedance. The gear pair lumped model is extensively studied by many researchers [1-3, 25-27]. One with time-varying stiffness is adopted here, and an impedance model is transformed directly from this lumped parameter representation. The spring-mass dynamic model of the gear pair is shown in Figure 3. Time-varying mesh stiffness excitation is applied, but nonlinear terms are ignored. Let the mesh element node displacement vector be $\mathbf{x}=$ $\left\{x_{p}, y_{p}, z_{p}, \theta_{x p}, \theta_{y p}, \theta_{z p}, x_{g}, y_{g}, z_{g}, \theta_{x g}, \theta_{y g}, \theta_{z g}\right\}^{T}$. Gear pair relative deflection $\delta$ along the line of action can be yielded from

$$
\delta=\mathbf{V}_{P}^{T} \mathbf{x}-e_{m},
$$

where $e_{m}$ is the composite mesh error [26, 27], and gear profile modification is treated as profile error here. $\mathbf{V}_{P}$ is the project vector transferring displacement to the line of action, which can be expressed as

$$
\begin{aligned}
\mathbf{V}_{P} & =\left[\cos \beta_{\mathbf{b}} \sin \varphi, \pm \cos \beta_{\mathbf{b}} \cos \varphi, \sin \beta_{\mathbf{b}},\right. \\
& \mp r_{p} \sin \beta_{\mathbf{b}} \sin \varphi,-r_{p} \sin \beta_{\mathbf{b}} \cos \varphi, \pm r_{p} \cos \beta_{\mathbf{b}}, \\
& -\cos \beta_{\mathbf{b}} \sin \varphi, \mp \cos \beta_{\mathbf{b}} \cos \varphi,-\sin \beta_{\mathbf{b}}, \\
& \left.\mp r_{g} \sin \beta_{\mathbf{b}} \sin \varphi,-r_{g} \sin \beta_{\mathbf{b}} \cos \varphi, \pm r_{g} \cos \beta_{\mathbf{b}}\right]^{T},
\end{aligned}
$$

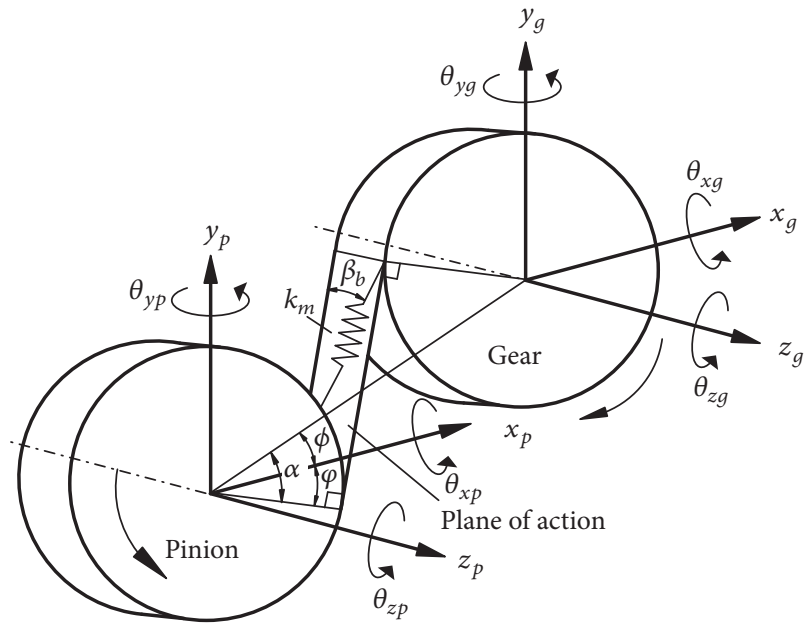

Figure 3: Dynamic model of gear pair.

where $r_{p}$ is the base circle radius of pinion, $r_{g}$ is the base circle radius of gear, $\beta_{\mathbf{b}}$ is the base helix angle, $\varphi=\alpha \mp \phi$ is the angle between the transverse line of action and $y$-axis, $\alpha$ is the mesh angle, $\phi$ is the fix angle, the top side of \pm or $\mp$ is for anticlockwise rotation of pinion, and the bottom side is for clockwise rotation of pinion.

Equations of motion of mesh element are established according to the Newton's second law and are given by

$$
\mathbf{M} \ddot{\mathbf{x}}(t)+\mathbf{C} \dot{\mathbf{x}}(t)+\mathbf{K}(t)(\mathbf{x}(t)-\mathbf{e}(t))=\mathbf{f}^{\mathrm{GP}}(t),
$$

where $\mathbf{M}=\operatorname{diag}\left\{m_{p}, m_{p}, m_{p}, I_{x p}, I_{y p}, I_{z p}, m_{g}, m_{g}, m_{g}, I_{x g}\right.$, $\left.I_{y g}, I_{z g}\right\} \mathbf{K}=k_{m} \mathbf{V}_{P} \mathbf{V}_{P}^{T}, \mathbf{C}=c_{m} \mathbf{V}_{P} \mathbf{V}_{P}^{T}$, $\mathbf{e}$ is the equivalent 
displacement vector of composite mesh error, $\mathrm{f}^{\mathrm{GP}}$ is the external force vector applied on the gear pair, that is, dynamic reaction force applied by the shafts here, $m_{i}(i=p, g)$ is the mass of pinion or gear, $I_{x i}, I_{y i}, I_{z i}(i=p, g)$ are the moment of inertia about $x, y$, and $z$, respectively, $k_{m}$ is the mesh stiffness, and $c_{m}$ is the mesh damping that can be expressed as

$$
c_{m}=2 \zeta \sqrt{\frac{\bar{k}_{m}}{\left(1 / m_{\mathrm{eq}, p}+1 / m_{\mathrm{eq}, g}\right)}},
$$

where $\zeta$ is the damping ratio that is generally equal to 0.03-0.17 [11, 28, 29], $\bar{k}_{m}$ is the mean mesh stiffness, and $m_{\mathrm{eq}, i}=I_{z i} / r_{i}^{2}$ is the equivalent mass of gear $i(i=p, g)$.

Time-varying mesh stiffness can be decomposed into constant part representing the average value and a fluctuating component,

$$
\mathbf{K}(t)=\mathbf{K}_{0}+\Delta \mathbf{K}(t),
$$

where $\mathbf{K}(t)$ is the time-varying mesh stiffness [27], $\mathbf{K}_{0}$ is the average stiffness, and $\Delta \mathbf{K}$ is the fluctuating component of stiffness. A combination of (3) and (5) yields

$$
\begin{aligned}
& \mathbf{M} \ddot{\mathbf{x}}(t)+\mathbf{C} \dot{\mathbf{x}}(t)+\mathbf{K}_{0} \mathbf{x}(t) \\
& \quad=\mathbf{f}^{\mathrm{GP}}-\Delta \mathbf{K}(t) \cdot \mathbf{x}(t)+\mathbf{K}(t) \cdot e(t) .
\end{aligned}
$$

As $\mathbf{x}(t)$ is unknown, let $\mathbf{x}(t) \approx \mathbf{x}_{s}(t)$ in the right side of the equation for approximation, and (6) then can be simplified as

$$
\mathbf{M} \ddot{\mathbf{x}}(t)+\mathbf{C} \dot{\mathbf{x}}(t)+\mathbf{K}_{0} \mathbf{x}(t)=\mathbf{f}^{\mathrm{GP}}+\mathbf{f}^{\text {mesh }},
$$

where $\mathbf{f}^{\text {mesh }}=-\Delta \mathbf{K}(t) \cdot \mathbf{x}_{s}(t)+\mathbf{K}(t) \cdot e(t), \mathbf{x}_{s}(t)=x_{s}(t) \mathbf{V}_{P}$, and $x_{s}(t)$ is the static transmission error.

$k_{m}(t), x_{s}(t)$, and $e(t)$ can be solved through method mentioned in [26].

Since displacement and force are periodic functions, they can be described in the Fourier series with a base frequency of gear mesh frequency. In the frequency domain, (7) can be transformed into the following term:

$$
\begin{aligned}
& \mathbf{M} \ddot{\mathbf{X}}(\omega)+\mathbf{C} \dot{\mathbf{X}}(\omega)+\mathbf{K}_{0} \mathbf{X}(\omega) \\
& \quad=\left(\mathrm{j} \omega \mathbf{M}+\mathbf{C}+\frac{\mathbf{K}_{0}}{\mathrm{j} \omega}\right) \dot{\mathbf{X}}(\omega)=\mathbf{F}^{\mathrm{GP}}(\omega)+\mathbf{F}^{\text {mesh }}(\omega) .
\end{aligned}
$$

Let $\mathbf{Z}^{\mathrm{GP}}(\omega)=\mathbf{j} \omega \mathbf{M}+\mathbf{C}+\mathbf{K}_{0} /(\mathbf{j} \omega)$ and $\mathbf{V}^{\mathrm{GP}}(\omega)=\dot{\mathbf{X}}(\omega)$; then the impedance equation of gear pair is given by

$$
\mathbf{Z}^{\mathrm{GP}} \mathbf{V}^{\mathrm{GP}}=\mathbf{F}^{\mathrm{GP}}+\mathbf{F}^{\text {mesh }},
$$

where $\mathbf{Z}^{\mathrm{GP}}$ is the gear pair impedance matrix, $\mathbf{V}^{\mathrm{GP}}$ is the gear pair velocity vector, $\mathrm{F}^{\mathrm{GP}}$ is the applied external force

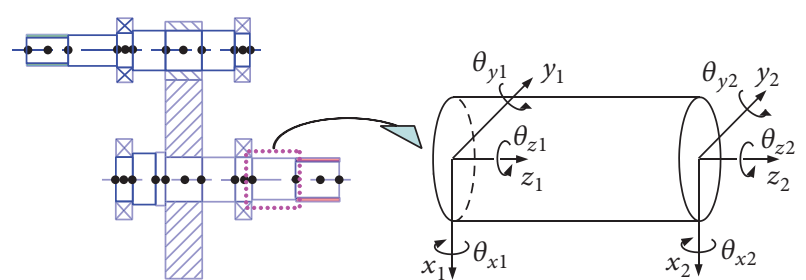

FIGURE 4: Model of the shaft structure.

vector, and $\mathbf{F}^{\text {mesh }}$ is the static transmission error excitation force vector.

2.2. Shaft Impedance. The shafts are divided into numerous segments, and each segment is modeled as a Timoshenko beam with 2 nodes and 6 degrees of freedom at each node as shown in Figure 4.

Let the general displacement vector of shaft segment beam element be $\mathbf{x}=\left\{x_{1}, y_{1}, z_{1}, \theta_{x 1}, \theta_{y 1}, \theta_{z 1}, x_{2}, y_{2}, z_{2}, \theta_{x 2}\right.$, $\left.\theta_{y 2}, \theta_{z 2}\right\}^{T} \cdot x_{i}, y_{i}, z_{i}(i=1,2)$ are displacement of node $i$ along direction of local coordinate, respectively, and $\theta_{x i}, \theta_{y i}, \theta_{z i}(i=$ $1,2)$ are angle of node $i$ rotated about the corresponding axis.

The transverse shear parameter is

$$
\Phi=\frac{12 E I}{\kappa A G l^{2}},
$$

where $E$ is Young's modulus, $I$ is the area moment of inertia, $\kappa$ is the shape factor, $\kappa=6(1+v) /(7+6 v)$ for a solid shaft, $v$ is the Poisson's Ratio, $A$ is the shaft cross-sectional area, $G$ is the shear modulus, and $l$ is the element length.

The radius of gyration is defined as

$$
r_{g}=\sqrt{\frac{I}{A}}
$$

The shaft element mass matrix is given by [30]

$$
\begin{aligned}
& \mathbf{M}^{\mathrm{e}}
\end{aligned}
$$

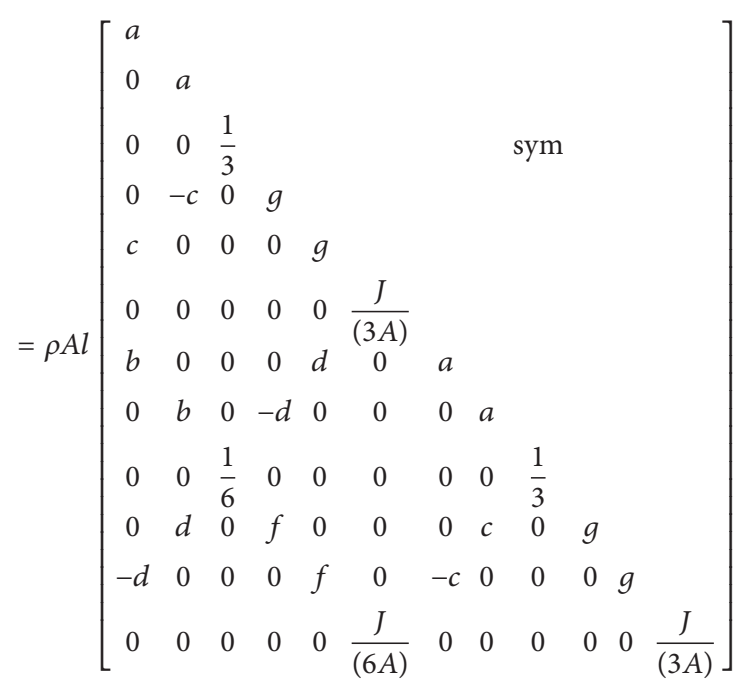


The shaft element stiffness matrix is given by [30]

$$
\begin{aligned}
& \mathbf{K}^{\mathbf{e}} \\
& =\left[\begin{array}{cccccccccccc}
a & & & & & & & & & & \\
0 & a & & & & & & & & & \\
0 & 0 & \frac{A E}{l} & & & & & & & & \\
0 & -b & 0 & c & & & & & & & \\
b & 0 & 0 & 0 & c & & & & & & \\
0 & 0 & 0 & 0 & 0 & \frac{G J}{l} & & & & & & \\
-a & 0 & 0 & 0 & -b & 0 & a & & & & \\
0 & -a & 0 & b & 0 & 0 & 0 & a & & & \\
0 & 0 & -\frac{A E}{l} & 0 & 0 & 0 & 0 & 0 & \frac{A E}{l} & & \\
0 & -b & 0 & d & 0 & 0 & 0 & b & 0 & c & \\
b & 0 & 0 & 0 & d & 0 & -b & 0 & 0 & 0 & c & \\
0 & 0 & 0 & 0 & 0 & -\frac{G J}{l} & 0 & 0 & 0 & 0 & 0 & \frac{G J}{l}
\end{array}\right] .
\end{aligned}
$$

The shaft mass matrix $\mathbf{M}$ and the stiffness matrix $\mathbf{K}$ can be yielded through a matrix assembly according to element nodes.

The shaft damping matrix can be described as the Rayleigh damping.

Motion equation of shafts can be yielded by

$$
\mathbf{M} \ddot{\mathbf{x}}+\mathbf{C} \dot{\mathbf{x}}+\mathbf{K x}=\mathbf{f}^{s}
$$

Equation (14) can be transformed into (15) in the frequency domain

$$
\mathbf{M X}(\omega)+\mathbf{C X}(\omega)+\mathbf{K X}(\omega)=\mathbf{F}^{\mathbf{s}}
$$

Impedance equation of shaft is expressed as

$$
\mathbf{Z}^{s} \mathbf{V}^{s}=\mathbf{F}^{s}
$$

2.3. Bearing Impedance. Bearing is modeled as a spring and a damper acting in parallel and connected through two coincident nodes. The 1st node is connected to the shafts and the 2 nd node is connected to the housing. Bearing stiffness matrix [31] is defined in (17). Nonlinear time-varying bearing stiffness [20] is ignored to simplify the problem, and only an average value is used here. Angular contact ball bearings are used in this study, and the detailed numerical scheme for $K_{m}$ can be found in [31].

$$
[K]_{m}=\left[\begin{array}{ll}
\frac{\partial F_{i m}}{\partial \delta_{j m}} & \frac{\partial F_{i m}}{\partial \beta_{j m}} \\
\frac{\partial M_{i m}}{\partial \delta_{j m}} & \frac{\partial M_{i m}}{\partial \beta_{j m}}
\end{array}\right]_{\{q\}_{m}} \quad(i, j=x, y, z)
$$

The final bearing stiffness matrix with six DOF per node is shown in (18).

$$
\begin{aligned}
\mathbf{K} & =\left[\begin{array}{ll}
\mathbf{K}_{11} & \mathbf{K}_{12} \\
\mathbf{K}_{21} & \mathbf{K}_{22}
\end{array}\right] \\
\mathbf{K}_{11} & =\mathbf{K}_{22}=-\mathbf{K}_{12}=-\mathbf{K}_{21} \\
& =\left[\begin{array}{cccccc}
k_{x x} & k_{x y} & k_{x z} & k_{x \theta x} & k_{x \theta y} & 0 \\
k_{y x} & k_{y y} & k_{y z} & k_{y \theta x} & k_{y \theta y} & 0 \\
k_{z x} & k_{z y} & k_{z z} & k_{z \theta x} & k_{z \theta y} & 0 \\
k_{\theta x x} & k_{\theta x y} & k_{\theta x z} & k_{\theta x \theta x} & k_{\theta x \theta y} & 0 \\
k_{\theta y x} & k_{\theta y y} & k_{\theta y z} & k_{\theta y \theta x} & k_{\theta y \theta y} & 0 \\
0 & 0 & 0 & 0 & 0 & 0
\end{array}\right] .
\end{aligned}
$$

When bearing damping is taken into consideration, the bearing impedance matrix will be yielded,

$$
\mathbf{Z}^{\mathrm{Br}}(\omega)=\mathbf{C}+\frac{\mathbf{K}}{(\mathrm{j} \omega)} .
$$

The impedance matrix can be obtained as follows:

$$
\mathbf{Z}^{\mathrm{Br}} \mathbf{V}^{\mathrm{Br}}=\mathbf{F}^{\mathrm{Br}}
$$

where $\mathbf{Z}^{\mathrm{Br}}$ is the impedance matrix, $\mathbf{V}^{\mathrm{Br}}$ is the velocity vector, and $\mathbf{F}^{\mathrm{Br}}$ is the excitation force vector.

2.4. Gearbox Housing Impedance. The mobility matrix of gearbox housing can be measured from experiment directly, and housing impedance can be obtained through a matrix inversion of the mobility function. In this study, harmonic analysis is employed to simulate the experiment.

A finite element model of gearbox housing is built, as shown in Figure 5. The material is aluminum alloy, density is $2700 \mathrm{~kg} / \mathrm{m}^{3}$, Young's modulus is $7.1 \times 10^{10} \mathrm{~Pa}$, Poisson's ratio is 0.33 , and viscous damping ratio is $2 \%$. The housing is meshed with 4 nodes' tetrahedron element and with over 75,000 nodes and more than 310,000 elements. The bearing holes are coupled at external nodes which are connected with bearings, and the housing is fixed to the foundation through the bottom area.

Harmonic analysis within a frequency range of $1 \mathrm{~Hz}$ to $20 \mathrm{kHz}$ with a step of $1 \mathrm{~Hz}$ is adopted in this study, and the modal superposition method with 500 modes is used to solve this problem.

The equation of motion of housing is given by

$$
\mathbf{M} \ddot{\mathbf{x}}+\mathbf{C} \dot{\mathbf{x}}+\mathbf{K x}=\mathbf{f},
$$

where $\mathbf{M}$ is the mass matrix, $\mathbf{C}$ is the damping matrix, $\mathbf{K}$ is the stiffness matrix, $\mathbf{x}$ is the nodal displacement vector, $\dot{\mathbf{x}}$ is the velocity vector, $\ddot{\mathbf{x}}$ is the acceleration vector, and $\mathbf{f}$ is the external force vector.

Equation (22) can be converted to a modal form

$$
\ddot{y}_{i}+2 \omega_{i} \xi_{i} \dot{y}_{i}+\omega_{i}^{2} y_{i}=f_{i},
$$




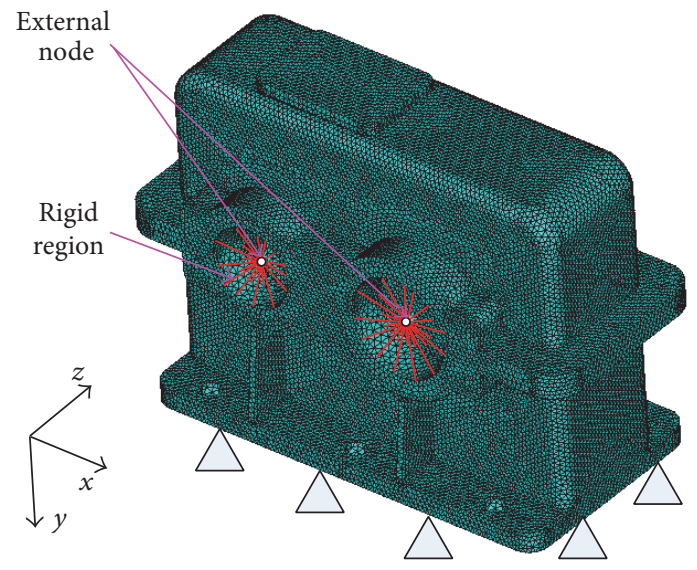

FIGURE 5: Finite element model of the housing.

where $y_{i}$ is the modal coordinate, $\omega_{i}$ is the natural circular frequency of mode $i, \xi_{i}$ is the fraction of critical damping for mode $i$, and $f_{i}$ is the force in modal coordinate. form

For a steady-state sinusoidal vibration, $f$ and $f_{i}$ have the

$$
\begin{aligned}
& f=f_{c} e^{j \Omega t}, \\
& f_{i}=f_{i c} e^{j \Omega t},
\end{aligned}
$$

where $f_{c}$ is the complex amplitude, $f_{i c}$ is the complex amplitude of the modal coordinate for mode $i, \mathrm{j}=\sqrt{-1}$, and $\Omega$ is the imposed circular frequency. To keep (23) true at all times, $y_{i}$ must have the following form:

$$
y_{i}=y_{i c} e^{\mathrm{j} \Omega t},
$$

where $y_{i c}$ is the complex amplitude of the modal coordinate for mode $i$. yields

Differentiating (25), substituting (24) and (25) into (23)

$$
\left(-\Omega^{2}+\mathrm{j} 2 \omega_{i} \Omega \xi_{i}+\omega_{i}^{2}\right) y_{i c}=f_{i c} .
$$

The complex displacement can be solved from

$$
\mathbf{x}_{c}=\sum_{i=1}^{n} \phi_{i} y_{i c}
$$

where $\phi_{i}$ is the modal shape for mode $i$.

Then the complex velocity can be obtained

$$
\mathbf{v}_{c}=\mathrm{j} \Omega \mathbf{x}_{c} .
$$

By applying unit force on term $j(j=1,2, \ldots, n)$, one will yield velocity at term $i(i=1,2, \ldots, n)$. Mobility matrix element $Y_{i j}$ can be obtained from

$$
Y_{i j}=\frac{v_{i}}{F_{j}}=\frac{v_{i c}}{F_{j c}} .
$$

Even though $Y_{i j}$ is solved by finite element method here, it can also be measured directly from experiment. A

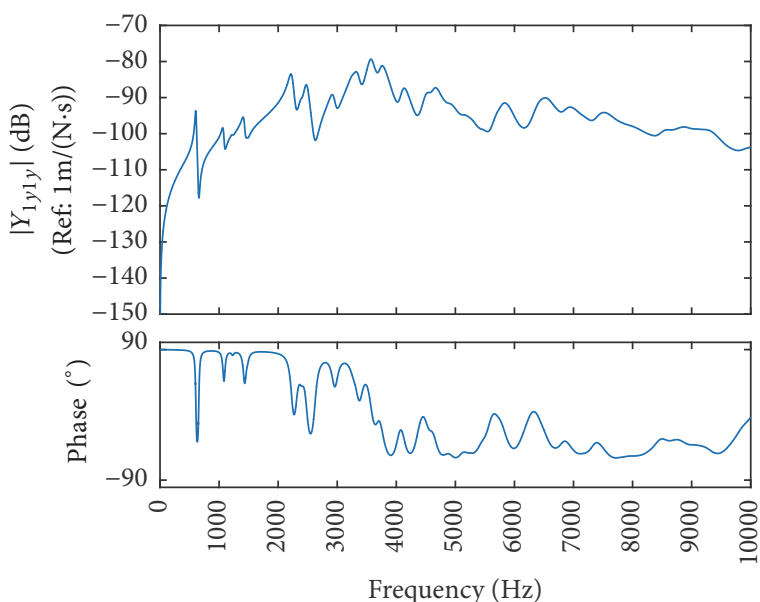

FIGURE 6: Driving point mobility at node 1 of the housing in the $y$ direction.

typical simulated mobility element is shown in Figure 6. Peak frequencies in the frequency-amplitude curve denote the natural frequencies of the housing.

In this study, only four external nodes with six degrees of freedom (DOF) per node are needed for further study, so the total DOF needed for housing impedances is $n=24$. When each mobility element $Y_{i j}(i=1,2, \ldots, n ; j=1,2, \ldots, n)$ has been solved, mobility matrix can be expressed as

$$
\mathbf{Y}=\left[\begin{array}{cccc}
Y_{11} & Y_{12} & \cdots & Y_{1 n} \\
& Y_{22} & \cdots & Y_{2 n} \\
& & \ddots & \vdots \\
\text { Sym. } & & & Y_{n n}
\end{array}\right]_{24 \times 24} .
$$

Impedance matrix can be obtained through a matrix inversion of $\mathbf{Y}$

$$
\mathbf{Z}^{\mathrm{GB}}=\mathbf{Y}^{-1}
$$

And the impedance equation yields

$$
\mathbf{Z}^{\mathrm{GB}} \mathbf{V}^{\mathrm{GB}}=\mathbf{F}^{\mathrm{GB}} .
$$

\section{Gear-Shaft-Bearing-Housing Impedance}

3.1. Impedance Synthesis. When all subsystem impedance models have been established, the impedances of gear pairs, shafts, bearings, and housing can be coupled through the impedance synthesis approach. For illustration facility, the degrees of freedom (DOF) of subsystems of gear pairs, shafts, bearings, and housing are rearranged according to the coupling relationship, and the corresponding impedance equations are presented below.

Gear pair element impedance equation is shown below as

$$
\left[\mathbf{Z}_{b}^{\mathrm{GP}}\right]\left\{\mathbf{V}_{b}^{\mathrm{GP}}\right\}=\left\{\mathbf{F}_{b}^{\mathrm{GP}}\right\}+\left\{\mathbf{F}^{\text {mesh }}\right\} .
$$




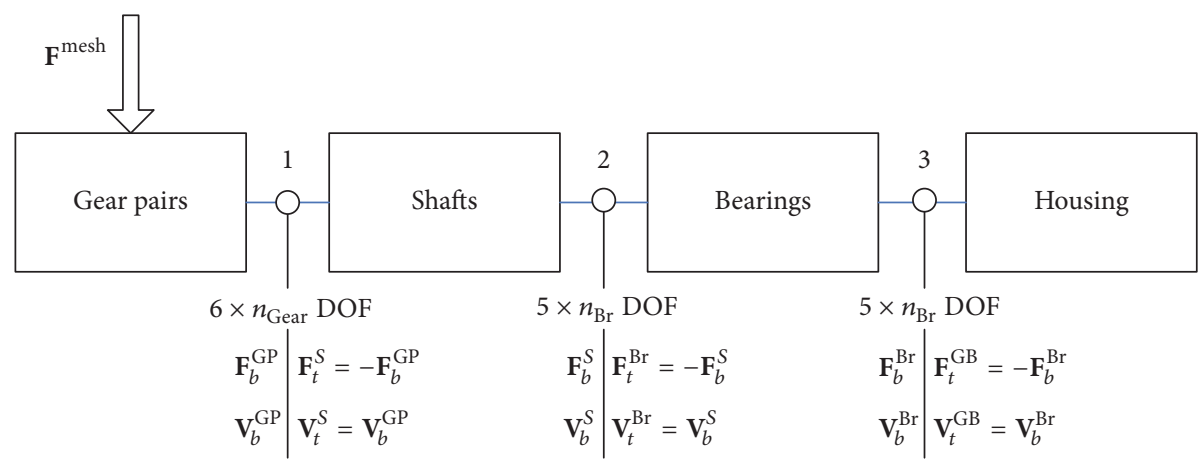

FIgURE 7: Coupling relationship between subsystems.

Shaft element impedance equation is expressed as

$$
\left[\begin{array}{ccc}
\mathbf{Z}_{t t}^{S} & \mathbf{Z}_{t m}^{S} & \mathbf{Z}_{t b}^{S} \\
\mathbf{Z}_{m t}^{S} & \mathbf{Z}_{m m}^{S} & \mathbf{Z}_{m b}^{S} \\
\mathbf{Z}_{b t}^{S} & \mathbf{Z}_{b m}^{S} & \mathbf{Z}_{b b}^{S}
\end{array}\right]\left\{\begin{array}{c}
\mathbf{V}_{t}^{S} \\
\mathbf{V}_{m}^{S} \\
\mathbf{V}_{b}^{S}
\end{array}\right\}=\left\{\begin{array}{c}
\mathbf{F}_{t}^{S} \\
\mathbf{F}_{m}^{S} \\
\mathbf{F}_{b}^{S}
\end{array}\right\} .
$$

Bearing element impedance equation is given by

$$
\left[\begin{array}{cc}
\mathbf{Z}_{t t}^{\mathrm{Br}} & \mathbf{Z}_{t b}^{\mathrm{Br}} \\
\mathbf{Z}_{b t}^{\mathrm{Br}} & \mathbf{Z}_{b b}^{\mathrm{Br}}
\end{array}\right]\left\{\begin{array}{c}
\mathbf{V}_{t}^{\mathrm{Br}} \\
\mathbf{V}_{b}^{\mathrm{Br}}
\end{array}\right\}=\left\{\begin{array}{c}
\mathbf{F}_{t}^{\mathrm{Br}} \\
\mathbf{F}_{b}^{\mathrm{Br}}
\end{array}\right\} .
$$

Housing element impedance equation is formulated as

$$
\left[\mathbf{Z}_{t}^{\mathrm{GB}}\right]\left\{\mathbf{V}_{t}^{\mathrm{GB}}\right\}=\left\{\mathbf{F}_{t}^{\mathrm{GB}}\right\} \text {, }
$$

where $\mathbf{Z}$ is the impedance matrix, $\mathbf{V}$ is the velocity vector, $\mathbf{F}$ is the excitation force vector, superscript GP means gear pair, $S$ means shaft, $B$ r means bearing, GB means gearbox or housing, subscript $b$ means bottom interface of subsystem in Figure 1 or right interface of subsystem in Figure 7, $t$ means top or left part, and $m$ means the middle part.

Coupling relationship is shown in Figure 7. The whole coupled model is a nonlinear system including nonlinear mesh stiffness and nonlinear bearing stiffness [20]; however, to simplify the problem, nonlinear time-varying mesh stiffness term is approximated as an average stiffness term and an excitation force term in (7), and nonlinear time-varying bearing stiffness is ignored here. So the whole model is simplified as a linear system which is suitable for the impedance method. Gear pairs and shafts are coupled through interface 1 , shafts and bearings are coupled through interface 2 , and bearings and gearbox housing are coupled through interface 3. Assume no external force acting at these interfaces, and only transmission error excitation is applied on the gear pair. The continuity equations and force equilibrium equations are also shown in Figure 7. Since static force and displacement have no direct influence on vibration and noise, they will be ignored here.

System impedance equation can be obtained through a combination of components impedance equations, continuity equations, and force equilibrium equations, or directly by assembling impedance matrix element according to node number

$$
\begin{aligned}
& {\left[\begin{array}{cccc}
\mathbf{Z}_{b}^{\mathrm{GP}}+\mathbf{Z}_{t t}^{S} & \mathbf{Z}_{t m}^{S} & \mathbf{Z}_{t b}^{S} & \mathbf{0} \\
\mathbf{Z}_{m t}^{S} & \mathbf{Z}_{m m}^{S} & \mathbf{Z}_{m b}^{S} & \mathbf{0} \\
\mathbf{Z}_{b t}^{S} & \mathbf{Z}_{b m}^{S} & \mathbf{Z}_{b b}^{S}+\mathbf{Z}_{t t}^{\mathrm{Br}} & \mathbf{Z}_{t b}^{\mathrm{Br}} \\
\mathbf{0} & \mathbf{0} & \mathbf{Z}_{b t}^{\mathrm{Br}} & \mathbf{Z}_{b b}^{\mathrm{Br}}+\mathbf{Z}_{t}^{\mathrm{GB}}
\end{array}\right]\left\{\begin{array}{c}
\mathbf{V}_{b}^{\mathrm{GP}} \\
\mathbf{V}_{m}^{S} \\
\mathbf{V}_{t}^{\mathrm{Br}} \\
\mathbf{V}_{b}^{\mathrm{Br}}
\end{array}\right\}} \\
& \quad=\left\{\begin{array}{c}
\mathbf{F}^{\mathrm{mesh}} \\
\mathbf{0} \\
\mathbf{0} \\
\mathbf{0}
\end{array}\right\} .
\end{aligned}
$$

Impedance $\mathbf{Z}$ and force $\mathbf{F}$ in (37) are known, so velocity which is unknown can be solved from the equation below

$$
\mathbf{V}(\omega)=\mathbf{Z}(\omega)^{-1} \mathbf{F}(\omega) .
$$

Displacement vector can then be obtained as

$$
\mathbf{X}(\omega)=\frac{\mathbf{V}(\omega)}{\mathbf{j} \cdot \omega}
$$

where $\mathbf{X}$ is the displacement vector, $\mathbf{V}$ is the velocity vector, $\mathrm{j}=\sqrt{-1}$, and $\omega$ is the circular frequency.

Displacement in time domain can be formulated as

$$
\mathbf{x}(t)=\mathbf{x}_{0}+\sum_{i_{\mathrm{GP}}=1}^{n_{\mathrm{GP}}} \sum_{k=1}^{K} \mathbf{X}\left(k \cdot \omega_{i_{\mathrm{GP}}}\right) \cdot e^{j k \omega_{i_{\mathrm{GP}}} t},
$$

where $\mathbf{x}_{0}$ is the static displacement, $i_{\mathrm{GP}}$ is the index of gear pairs, $n_{\mathrm{GP}}$ is the number of gear pairs, $k$ is the index of harmonic component, $K$ is the maximum harmonic order, $\mathrm{j}=\sqrt{-1}$, and $\omega_{i_{\mathrm{GP}}}$ is the mesh frequency of gear pair $i_{\mathrm{GP}}$.

3.2. Model Validation. Even though conventional lumped parameter model can incorporate an equivalent mass matrix and stiffness matrix of housing into the whole system $[9,10,18,20]$, they failed to take into consideration the housing impedance directly when the housing model is not given and only impedance is known. In order to compare 


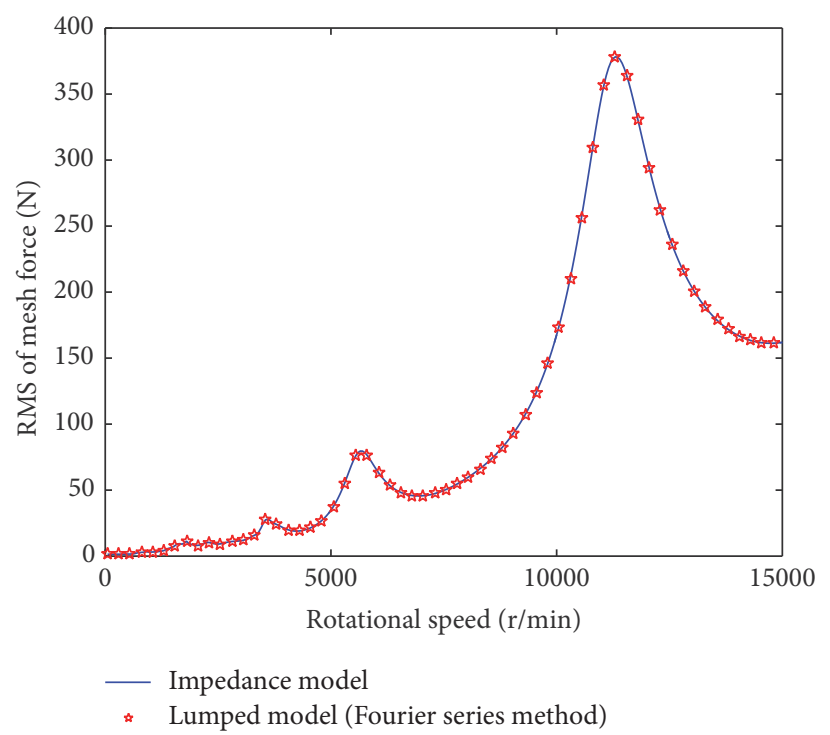

(a)

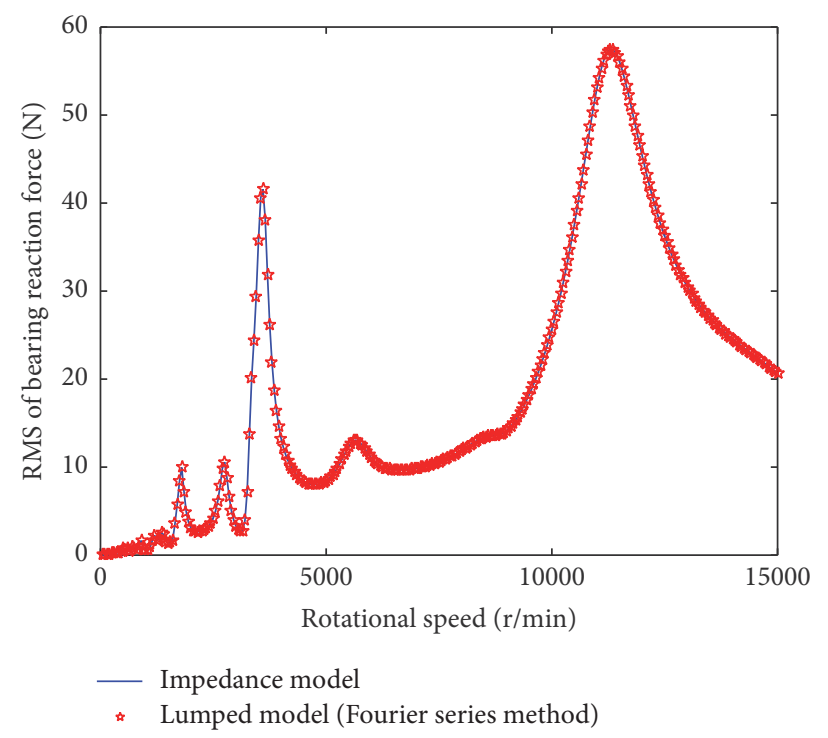

(b)

FIGURE 8: Comparison between impedance model and lumped parameter model: (a) RMS of mesh force; (b) RMS of bearing reaction load.

the impedance model with the lumped model, the geared transmission system (without housing) is studied by both impedance synthesis method and lumped method. In this case, the impedance model can be transformed directly from the lumped model [27], and the only difference occurs between the solving processes. Natural frequencies are computed for both impedance model and lumped model, and they yield the same results. The root mean square (RMS) of mesh force and bearing reaction loads for rigid housing configuration at different rotational speeds are computed by both Fourier series method [27] and impedance method. Here, the system total DOF is 150 , and it takes about 14 seconds to compute system vibration at 600 different speeds for impedance method while taking 77 seconds for Fourier series method using a relatively modern computer. A good coincidence between the two methods is shown in Figure 8.

For a gear-shaft-bearing-housing coupled case, a FE model is built, as shown in Figure 9. The gear pair is modeled as two masses connected by a mesh spring. Bearings are modeled as springs. Shafts and the housing are represented with 4-node tetrahedron elements with a maximum element size of $5 \mathrm{~mm}$. The shaft material is steel and the housing material is aluminum alloy. There are more than 120,000 nodes and nearly 600,000 elements in total. The block Lanczos method is adopted to extract the modal frequency, while, in the impedance model, system DOF is 174 and frequency is swept from $0.1 \mathrm{~Hz}$ to $5000 \mathrm{~Hz}$ with a step of $0.1 \mathrm{~Hz}$ to solve the natural frequency.

Natural frequencies are obtained for the impedance model and the FEM, respectively, and the results are listed in Table 3. The maximum relative error is $3.2 \%$.

\section{Effect of Housing Impedance}

4.1. Effect of Housing on System Natural Frequency. Damping terms are ignored in this section. Each mobility element

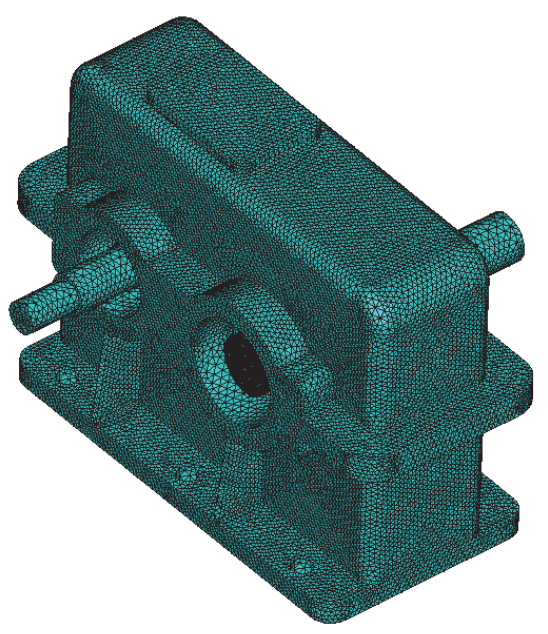

FIGURE 9: Finite element model of the coupled model.

TABLE 3: Validation of the natural frequency.

\begin{tabular}{lccc}
\hline Modes & Impedance model $(\mathrm{Hz})$ & FEM $(\mathrm{Hz})$ & Relative error \\
\hline 1 & 267.7 & 269.6 & $0.7 \%$ \\
2 & 311.8 & 321.8 & $3.1 \%$ \\
3 & 337.6 & 346.8 & $2.7 \%$ \\
4 & 593.8 & 613.7 & $3.2 \%$ \\
5 & 612.6 & 623.0 & $1.7 \%$ \\
\hline
\end{tabular}

is a function of frequency, and natural frequencies are the peak frequencies of these frequency-mobility curves. It is challenging to recognize all modes on a single frequencymobility curve; however it is possible to find all modes when all mobility matrix elements are taken into consideration. Summation function denoted as SUM is the sum of all 


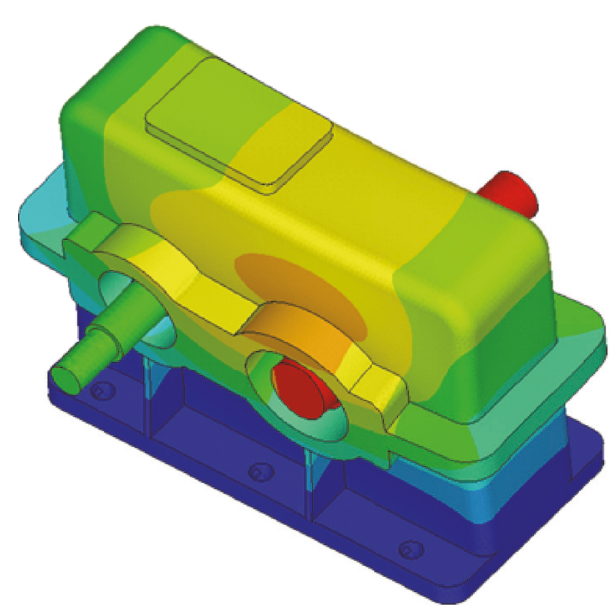

(a)

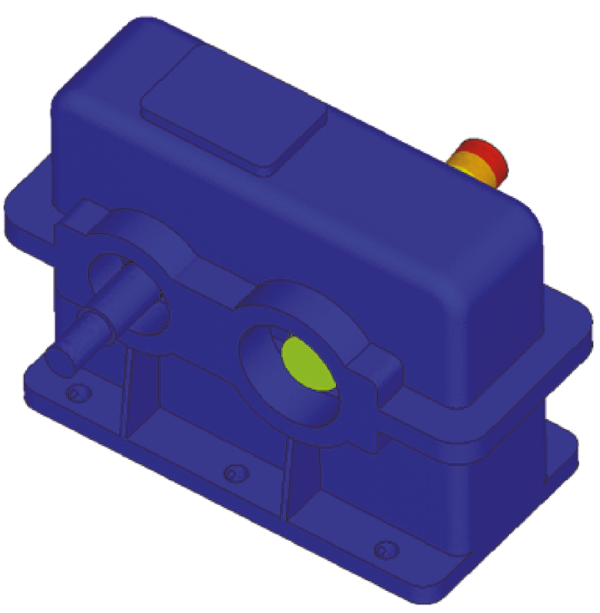

(c)

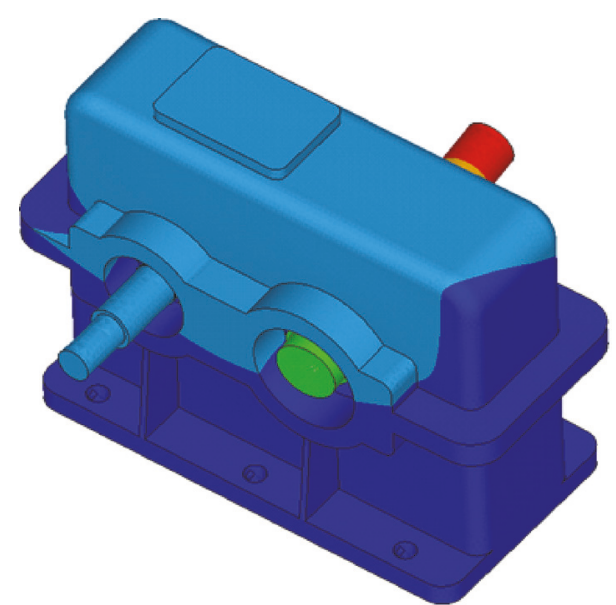

(b)

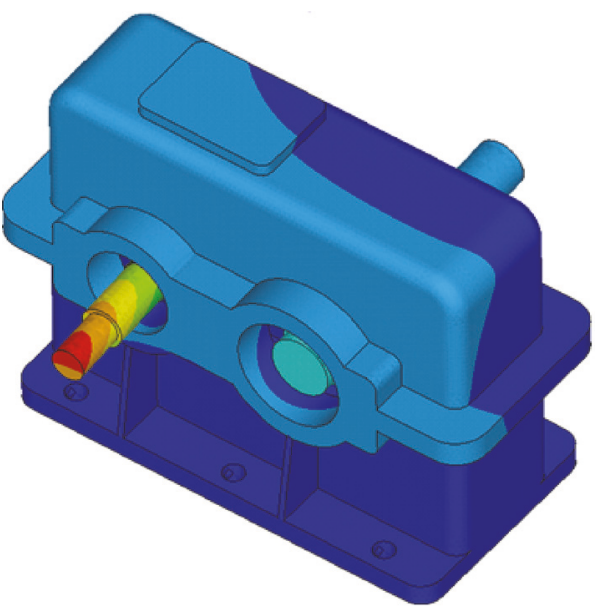

(d)

FIGURE 10: Mode shapes of the whole coupled system: (a) 1st mode; (b) 2nd mode; (c) 3rd mode; (d) 4th mode.

mobility matrix elements. The seeking process of identifying the peak at each natural frequency is adopted here to find the system natural frequency. This analysis is given by

$$
\mathrm{SUM}=\sum_{i=1}^{n} \sum_{j=1}^{n}\left|Y_{i j}\right|
$$

Frequency is swept from $0.1 \mathrm{~Hz}$ to $5000 \mathrm{~Hz}$ with a step of $0.1 \mathrm{~Hz}$ to find peak frequencies of the summation function, and the first 5 system natural frequencies are listed in Table 4. When the gearbox housing is coupled to the transmission system, system natural frequency decreases significantly.

It is difficult to show the mode shapes of the whole system using the impedance model, because only four external nodes are used to represent the structure of the housing. In order to study the mode shapes, a FE model shown in Section 3.2 is used instead of the impedance model.

The first four mode shapes of the whole coupled system are shown in Figure 10. The 1st mode is a composite motion of the whole system, and the housing is strongly coupled with the shafts. The 2 nd mode is mainly the swing motion of the output shafts, with the input shaft and the housing slightly
TABLE 4: System natural frequency $(\mathrm{Hz})$.

\begin{tabular}{lccc}
\hline Modes & $\begin{array}{c}\text { Transmission } \\
\text { system }\end{array}$ & Housing & $\begin{array}{c}\text { Gear-housing } \\
\text { coupled system }\end{array}$ \\
\hline 1 & 323.0 & 607.0 & 267.7 \\
2 & 350.5 & 1074.6 & 311.8 \\
3 & 499.1 & 1228.4 & 337.6 \\
4 & 651.7 & 1422.2 & 593.8 \\
5 & 726.2 & 1479.7 & 612.6 \\
\hline
\end{tabular}

coupled. The 3rd mode is mainly the flexural deformation of the output shaft. The 4 th mode is mainly the flexural deformation of the input shaft, with the output shaft and the housing slightly coupled.

4.2. Effect of Housing on Dynamic Mesh Force. When the system dynamic displacement is solved from (42), the DTE (dynamic transmission error) can be obtained as

$$
\mathrm{DTE}=\mathbf{V}_{P}^{T} \mathbf{x}_{m},
$$




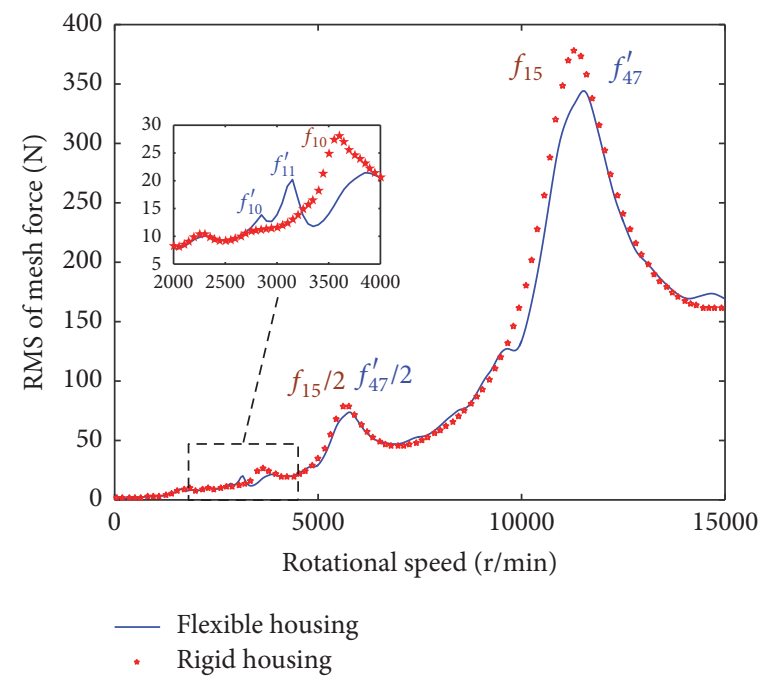

(a)

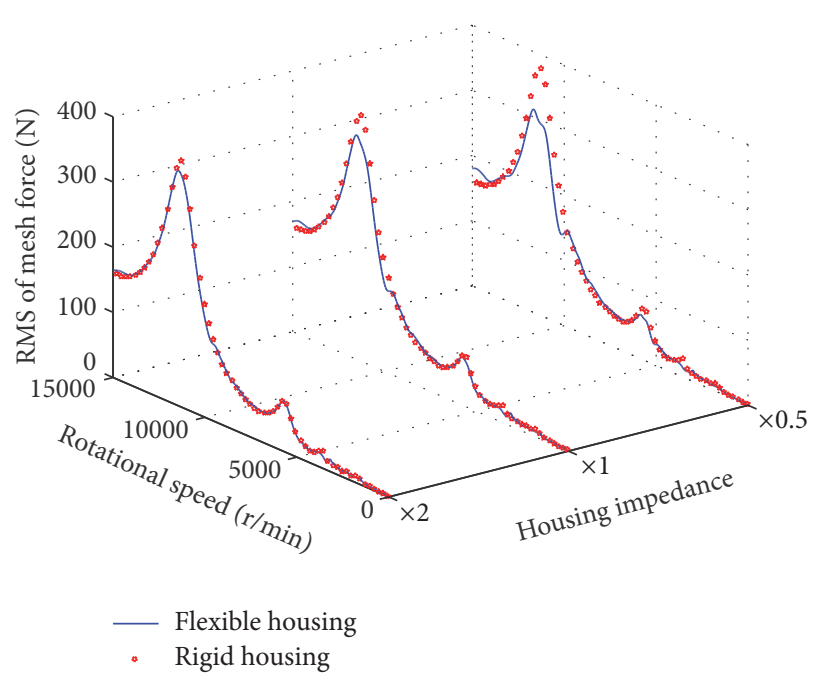

(b)

FIGURE 11: Housing influence on RMS of dynamic mesh force: (a) Original housing impedance; (b) modified housing impedances.

where $\mathbf{V}_{P}$ is the project vector shown in (2) and $\mathbf{x}_{m}$ is the displacement of mesh element.

Dynamic mesh force of gear pair can be formulated as

$$
F_{d}=k_{m} \cdot\left(\mathrm{DTE}-e_{m}\right)+c_{m} \cdot \mathrm{DTE},
$$

where $k_{m}$ is the mesh stiffness, $c_{m}$ is the mesh damping, DTE is the dynamic transmission error, DTE is the time derivative of DTE, and $e_{m}$ is the composite mesh error.

The root mean square (RMS) of mesh force for both a rigid housing configuration and a flexible one is computed through impedance synthesis approach to study the influence of housing flexibility on gear vibration. Results are shown in Figure 11.

In Figure 11(a), the two highest gear vibration peaks occur at $f_{15} / 2$ and $f_{15}$ in the rigid housing configuration, in which $f_{15}$ means the 15th system natural frequency of the rigid housing configuration and $f_{15} / 2$ means half of that value. Since housing flexibility has changed the system natural frequency, the corresponding two highest components moved to $f_{47}^{\prime} / 2$ and $f_{47}^{\prime}$ in the flexible housing configuration, in which $f_{47}^{\prime}$ means the 47 th system natural frequency of the flexible housing configuration, and $f_{47}^{\prime} / 2$ means half of that value. When housing impedance is considered, the two highest RMS of mesh force reduce $7.4 \%$ and $9.0 \%$, respectively.

Though housing impedance has little effect on the peak mesh force, it greatly influences the gear vibration within the speed range of $2000-4000 \mathrm{r} / \mathrm{min}$. The peak corresponding to the $f_{10}$ natural frequency disappears and new peaks corresponding to $f_{10}^{\prime}$ and $f_{11}^{\prime}$ emerge when the housing is coupled with the geared transmission system. The peak values decrease $28.1 \%$ when the housing is taken into consideration.

In order to investigate influence of different housing compliance levels on gear vibration, housing impedance is multiplied by 2 and 0.5 , respectively, and the results are compared and shown in Figure 11(b). For the gearbox with the stiffer housing $\left(Z^{\mathrm{GB}} \times 2\right)$, the main peak value reduces only $4.5 \%$ compared to the rigid housing case. For the original housing configuration, the peak reduces $9.0 \%$. For the softer housing $\left(Z^{\mathrm{GB}} \times 0.5\right)$ one, the peak reduces $17.6 \%$. This means that the housing with lower impedance has more potential influence on the gear vibration.

4.3. Effect of Housing on Bearing Reaction Load. Bearing reaction load can be computed from (35) by solving for the system velocity. The RMS function of the 1st bearing reaction load at different rotational speed is shown in Figure 12.

Housing flexibility is noted to contribute greatly to the RMS of bearing reaction load. Also, the following specific observations are seen. (1) The two main peak frequencies for the rigid housing configuration are corresponding to the 10th natural frequency and the 15th natural frequency. For the flexible housing, these frequencies are changed to the 10th natural frequency and the 47th natural frequency. (2) When flexible housing has been taken into consideration, the first main critical speed decreases 20.8\%. (3) About 33.7\% peak amplitude reductions are seen for the first main resonance peak. (4) New peaks such as those corresponding to the 28th and 33rd natural frequency emerge when housing impedance is considered. (5) Housing increases bearing reaction load fluctuation at some operation speeds but decreases it at some other speeds, which has a good agreement with results reported by Parker et al. [8].

The RMS function of bearing reaction load for modified housing impedances is shown in Figure 12(b). When the housing has been coupled with the geared transmission system, the first main peak frequency shifts $-15.3 \%,-20.8 \%$, and $-29.2 \%$, respectively, for the stiffened housing configuration, the original case, and the softened one. Vibration amplitude decreases $49.5 \%, 33.7 \%$, and $56.3 \%$, respectively, for the stiffened housing, the original housing, and the softened one. The housing with lower impedance has more potential influence on bearing reaction load. More peaks appear when the housing is softened. 


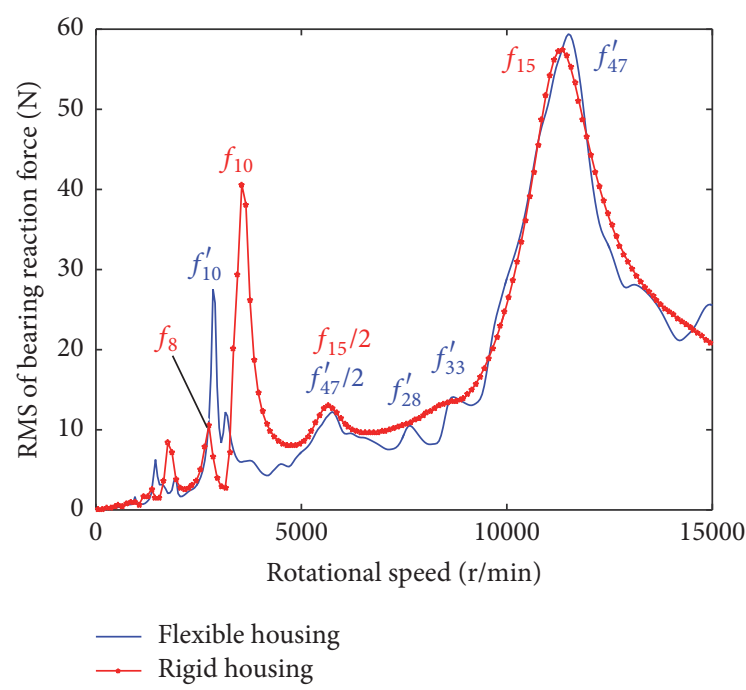

(a)

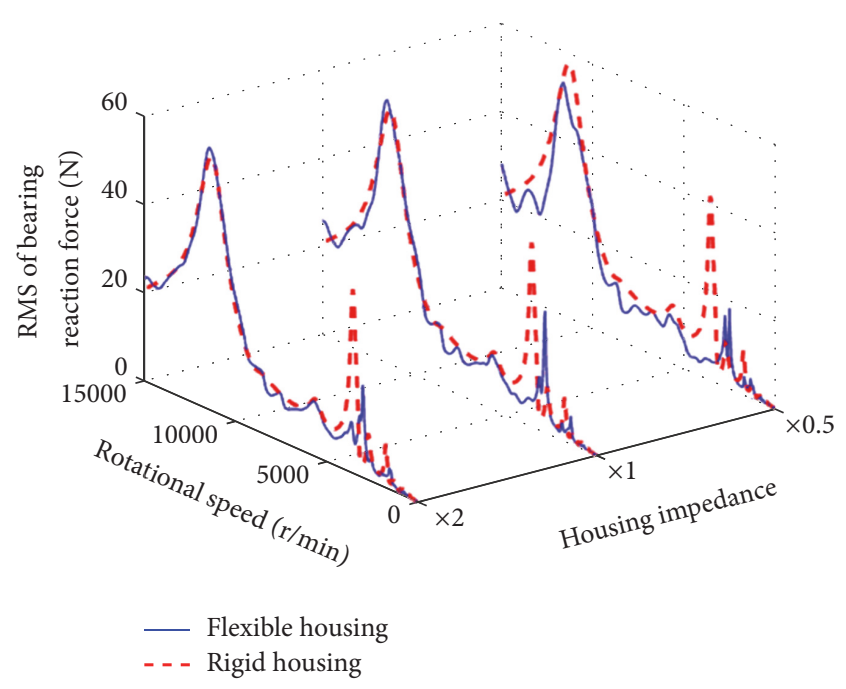

(b)

FIGURE 12: Housing influence on the RMS of dynamic force of the 1st bearing: (a) original housing impedance; (b) modified housing impedances.

\section{Effect of Bearing on Housing Contribution}

A bearing structure will propagate structure-borne noise from the shaft to the housing, and it also plays an important role on the housing contribution on geared transmission system vibration. However, bearing stiffness and damping are difficult to calculate exactly, and currently any bearing vibration model will be a simplified approximation [32]. In order to evaluate the housing contribution on system dynamics, a parametric study of bearing characteristics is applied. Since average bearing stiffness [31] and damping are used in this model, only stiffness and damping influences are studied here.

The RMS function of mesh force for different bearing stiffness models with both rigid housing and flexible one is computed, and results are shown in Figure 13(a). Damping is kept constant in order to study the influence of bearing stiffness. As bearing displays a dashpot behavior in the propagation of structure-borne noise, it only allows relative motion at low frequencies. When bearing stiffness increases, gear vibration increases too. Comparison between rigid housing models and flexible ones with different bearing stiffness shows that housing reduces the amplitude by $3.5 \%, 9.0 \%$, and $11.9 \%$ for the softened bearing model, the original one, and the stiffened one, respectively.

In order to study the influence of bearing damping on the housing contribution on mesh force, different bearing damping is used while bearing stiffness remains constant. Results are shown in Figure 13(b). Since damping will reduce vibration amplitude, peak value decreases as bearing damping increases. When the housing impedance is considered, the peak amplitude reduces about $4.6 \%, 9.0 \%$, and $9.6 \%$ for 10 times' bearing damping model, the original damping one, and 0.1 times' damping one, respectively.

The RMS function of bearing reaction load for different bearing stiffness with a rigid housing and a flexible one is shown in Figure 13(c). Bearing stiffness not only influences system dynamic characteristics and bearing vibration directly, but also has significant influence on the housing contribution on bearing reaction load. As bearing stiffness increases, $-11.3 \%,-20.8 \%$, and $-25.3 \%$ peak frequency shifts are yielded, and $32.9 \%,-33.7 \%$, and $-69.5 \%$ peak value changes are obtained, respectively, for the first main peaks. New peaks emerge as bearing stiffness increases.

Influence of bearing damping on housing contribution on bearing reaction load is shown in Figure 13(d). As bearing damping decreases, $-23.7 \%,-20.8 \%$, and $-20.8 \%$ peak frequency shifts are obtained, and $-34.0 \%,-33.7 \%$, and $-45.2 \%$ peak value changes can be observed for the first main peaks.

Comparison between Figures 13(a), 13(b), 13(c) and 13(d) shows that housing compliance has limited influence on gear vibration, but it will affect the bearing reaction load significantly. Bearing stiffness has prominent influence on the contribution of housing compliance on system vibration. When bearing stiffness increases, the housing influence on system dynamic characteristics increases.

\section{Conclusions}

The main objective of this paper is to incorporate housing impedance with the gear transmission system when the housing model is not given and only the impedance is known. A coupled gear-shaft-bearing-housing dynamic model is developed applying the impedance synthesis approach. Though the whole system is nonlinear, an approximate linear model is used to simplify the problem. The static transmission error excitation is applied on the model while the nonlinear timevarying bearing stiffness excitation is ignored for simplification. The proposed method is convenient to model and efficient to compute. Impedances of gear pairs, shafts, and bearings are transformed directly from lumped parameter representations, and the housing impedance is obtained through harmonic analysis instead of using an experimental 


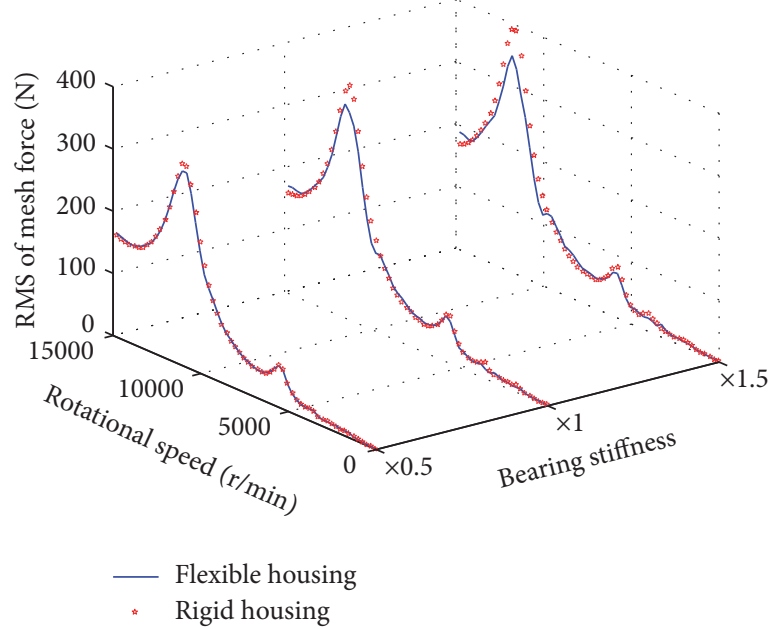

(a)

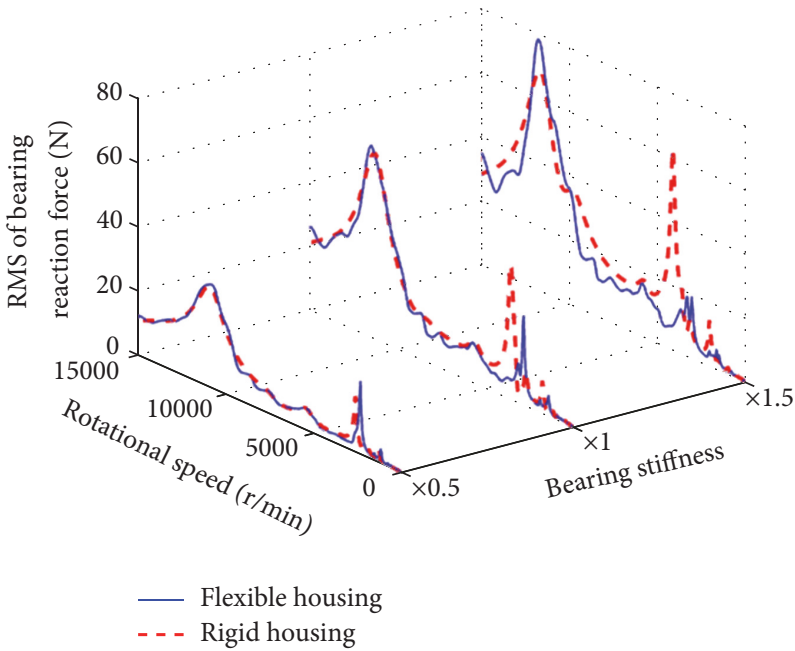

(c)

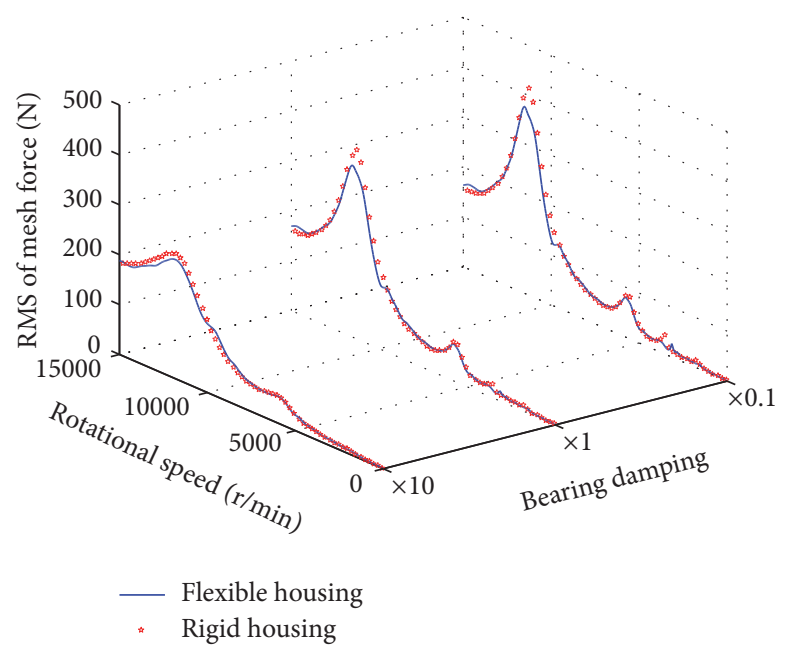

(b)

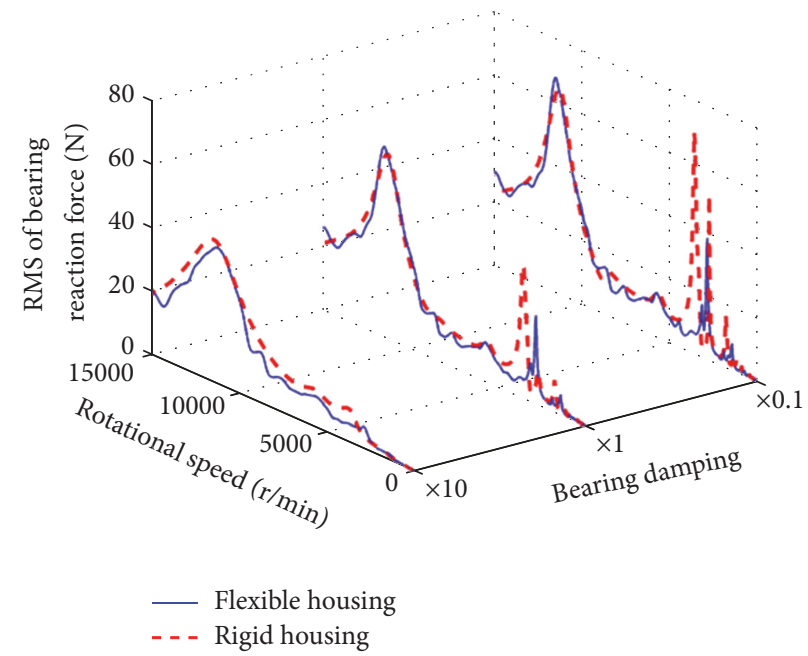

(d)

FIGURE 13: Influence of bearing properties on housing contribution on system vibration: (a) bearing stiffness, mesh force; (b) bearing damping, mesh force; (c) bearing stiffness, bearing reaction load; (d) bearing damping, bearing reaction load.

setup. Influence of housing impedance on system dynamic is analyzed. Specific conclusions are listed below.

(1) The housing compliance will decrease the system natural frequency and induces new natural frequencies as compared to rigid foundation assumption.

(2) Housing impedance has limited influence on gear vibration but will affect bearing reaction load significantly. The specific influence of the housing on the RMS function of bearing reaction load depends on the operating speed.

(3) Bearing stiffness has significant influence on housing contribution to the overall system vibration. For a stiffer bearing configuration, the housing influence will be more prominent.

(4) The impedance synthesis model proposed in this study is able to combine theoretical parameters with experimental data, which provides an effective way to couple complex housing and foundation with the transmission system. Also, the impedance method is computationally more efficient than the Fourier series method when performing the dynamic response calculation.

(5) It takes more computational time for the impedance model than the lumped parameter model in the modal analysis. Also, the impedance method cannot be adopted directly in a nonlinear analysis.

Further study is needed to take into consideration the nonparallel gearing condition caused by housing deformation and the time-varying bearing stiffness excitation.

\section{Nomenclature}
A: Section area
$c_{m}$ : Mesh damping
C: Damping matrix 
DTE: Dynamic transmission error

E: Material Young's modulus

$\mathbf{e}_{m}$ : Composite mesh error

f: $\quad$ External force vector

$\mathbf{f}_{\text {mesh }}$ : Excitation force vector

F: $\quad$ External force vector in frequency domain

$F_{j}: \quad$ Force/moment applied at point $j$

$\mathbf{F}^{\text {mesh }}$ : Excitation force in frequency domain

G: $\quad$ Material shear elastic modulus

I: $\quad$ Area moment of inertia

$I_{i}: \quad$ Moment of inertia

$\mathrm{j}: \quad \mathrm{j}=\sqrt{-1}$

$J: \quad$ Polar moment of inertia

$k_{m}: \quad$ Mesh stiffness

K: $\quad$ Stiffness matrix

$\Delta \mathbf{K}: \quad$ Fluctuant component of stiffness matrix

$\mathbf{K}_{0}$ : $\quad$ Average stiffness matrix

$L: \quad$ Length

$m_{\text {eq }, i}:$ Equivalent mass of gear $i(i=p, g)$

$m_{i}: \quad$ Mass of pinion or gear $(i=p, g)$

M: $\quad$ Mass matrix

$n_{\mathrm{Br}}: \quad$ Number of bearings

$n_{\text {Gear }}:$ Number of gears

$n_{\mathrm{GP}}: \quad$ Number of gear pairs

OD: Outer diameter

$r_{i}: \quad$ Base circle radius of pinion or gear $(i=p, g)$

SUM: Summation function

$v_{i}: \quad$ Translation/rotation velocity measured at point $i$

V: Velocity vector

$\mathbf{V}_{P}:$ Project vector

$x_{s}: \quad$ Static transmission error

x: $\quad$ Displacement vector

$\mathbf{X}$ : Displacement vector in frequency domain

$y_{i}$ : Modal coordinate

Y: $\quad$ Mobility matrix

$Y_{i j}$ : $\quad$ Mobility matrix element

$\mathrm{Z}: \quad$ Impedance matrix

$\alpha: \quad$ Mesh angle

$\alpha_{0}$ : Mass scale factor

$\alpha_{1}: \quad$ Stiffness scale factor

$\beta_{\mathbf{b}}$ : Base helix angle

$\delta: \quad$ Gear pair relative deflection along the line of action

$\varphi$ : $\quad$ Angle between transverse line of action and $y$-axis

$\phi: \quad$ Fix angle

$\phi_{i}: \quad$ Modal shape for mode $i$

$\Phi: \quad$ Transverse shear parameter

$\kappa: \quad$ Shape factor

$\rho: \quad$ Material density

$\theta: \quad$ Rotation angle of node $i$

$\omega: \quad$ Circular frequency

$\Omega: \quad$ Angular speed

$\zeta: \quad$ Damping ratio.

\section{Superscript}

Br: Bearing subsystem

GB: Gearbox or housing subsystem
GP: Gear pair subsystem

$H$ : Conjugate transpose

Sh: Shaft system

T: Matrix transpose.

\section{Subscript}

$b$ : Bottom interface part (in Figure 1)

g: Gear

$m$ : Middle or internal part (in Figure 1)

$p$ : Pinion

$t$ : Top interface part (in Figure 1).

\section{Conflicts of Interest}

The authors declare that there are no conflicts of interest regarding the publication of this paper.

\section{Acknowledgments}

This study is supported by the Key Project of National Science Foundation of China (Grant no. 51535009) and 111 Project (Grant no. B13044), China.

\section{References}

[1] P. Velex and V. Cahouet, "Experimental and numerical investigations on the influence of tooth friction in spur and helical gear dynamics," Journal of Mechanical Design, vol. 122, no. 4, pp. 515-522, 2000.

[2] A. Fernández, M. Iglesias, A. de-Juan, and etal., "Gear transmission dynamic: effects of tooth profile deviations and support flexibility," Applied Acoustics, vol. 77, pp. 138-149, 2014.

[3] L. Vedmar and A. Andersson, "A method to determine dynamic loads on spur gear teeth and on bearings," Journal of Sound and Vibration, vol. 267, no. 5, pp. 1065-1084, 2003.

[4] M. S. Abbes, S. Bouaziz, F. Chaari et al., "An acoustic-structural interaction modelling for the evaluation of a gearbox-radiated noise," Mechanical Sciences, vol. 50, pp. 569-577, 2008.

[5] M. S. Le and J. L. Tébec, "Ribs effects in acoustic radiation of a gearbox their modeling in a boundary element method," Applied Acoustics, vol. 63, pp. 223-233, 2002.

[6] S. A. Hambric, M. R. Shepherd, and R. L. Campbell, "Effects of gears, bearings, and housings on gearbox transmission shafting resonances," in Proceedings of ASME 2010 International Mechanical Engineering Congress and Exposition (IMECE '10), pp. 229-238, can, November 2010.

[7] C. C. Zhu, B. Lu, C. S. Song, and etal., "Dynamic analysis of a heavy duty marine gearbox with gear mesh coupling," Proceedings of the Institution of Mechanical Engineers, Part C: Journal of Mechanical Engineering Science, vol. 223, no. 11, pp. 2531-2547, 2009.

[8] R. G. Parker, Y. Guo, T. Eritenel, and etal., "Vibration propagation of gear dynamics in a gear-bearing-housing system using mathematical modeling and finite element analysis," NASA, 2012.

[9] Z. X. He, L. H. Chang, and L. Liu, "Dynamic response analysis of planetary gear transmission system coupled with gearbox vibration," Journal of South China University of Technology, vol. 9, pp. 128-134, 2015. 
[10] C. C. Zhu, X. Xu, H. Liu, and etal., "Research on dynamical characteristics of wind turbine gearboxes with flexible pins," Renewable Energy, vol. 68, pp. 724-732, 2014.

[11] H. Liu, C. Xiang, and S. Fu, "Research on dynamic coupled characteristics of a tracked vehicle gearbox," International Journal of Computational Intelligence Systems, vol. 4, no. 6, pp. 1204-1215, 2011.

[12] M. S. Abbes, T. Fakhfakh, M. Haddar, and etal., "Effect of transmission error on the dynamic behaviour of gearbox housing," International Journal of Advanced Manufacturing Technology, vol. 34, no. 3, pp. 211-218, 2007.

[13] T. E. Rook and R. Singh, "Mobility analysis of structure-borne noise power flow through bearings in gearbox-like structures," Noise Control Engineering Journal, vol. 44, no. 2, pp. 69-78, 1996.

[14] R. C. N. Leung and R. J. Pinnington, "Vibrational power transmission of an idealized gearbox," Journal of Sound and Vibration, vol. 128, no. 2, pp. 259-273, 1989.

[15] T. C. Lim and R. Singh, "A review of gear housing dynamics and acoustic literature," NASA, 1989.

[16] E. Rigaud and J. Sabot, "Effect of elasticity of shafts, bearings, casing and couplings on the critical rotational speeds of a gearbox," Arxiv Preprint Physics, Article ID 0701038, 2007.

[17] F. K. Choy, Y. K. Tu, J. J. Zakrajsek, and etal., "Effects of gear box vibration and mass imbalance on the dynamics of multistage gear transmission," Journal of Vibration and Acoustics, vol. 113, no. 3, pp. 333-344, 1991.

[18] Y. Guo, T. Eritenel, T. M. Ericson, and R. G. Parker, "Vibroacoustic propagation of gear dynamics in a gear-bearinghousing system," Journal of Sound and Vibration, vol. 333, pp. 5762-5785, 2014.

[19] M. Hajžman and V. Zeman, "Modelling of gearbox vibration and noise," PAMM, vol. 5, no. 1, pp. 93-94, 2005.

[20] J. C. Jauregui, I. Torres, R. Garcia, and A. Leon, "Housing stiffness influence on gearbox dynamic loading for wind turbine applications," in Proceedings of ASME Turbo Expo 2012: Turbine Technical Conference and Exposition, June 2012.

[21] X. Zhang, R. Huo, Y. Zhou, and Z. Zhou, "Research on power flow transmitted through rolling bearing in the gear shaft-plate coupled structure," Applied Mechanics and Materials, vol. 141, no. 1, pp. 442-448, 2012.

[22] W. J. Gao, L. Wang, and Y. G. Liu, "Analysis on vibration transmission characteristics of box-like power structure," Journal of Beijing University of Aeronautics and Astronautics, vol. 41, no. 3, pp. 509-516, 2015.

[23] M. A. Bowes and A. Berman, "Prediction of vibration and noise of a transmission using a dynamic model partially derived from test data," Institute of Environmental Sciences, vol. 77, pp. 334338, 1977.

[24] D. R. Houser, "Research in the gear dynamics and gear noise research laboratory," in Proceedings of 1982 SAE International Off-Highway and Powerplant Congress and Exposition, vol. 87, pp. 53-58.

[25] F. L. J. Van Der Linden, "Modeling of geared positioning systems: an object-oriented gear contact model with validation," Proceedings of the Institution of Mechanical Engineers, Part C: Journal of Mechanical Engineering Science, vol. 230, no. 7-8, pp. 1084-1100, 2016.

[26] L. Chang, G. Liu, and L. Wu, "A robust model for determining the mesh stiffness of cylindrical gears," Mechanism and Machine Theory, vol. 87, pp. 93-114, 2015.
[27] L. Chang, G. Liu, and L. Wu, "Determination of composite meshing errors and its influence on the vibration of gear system," Journal of Mechanical Engineering, vol. 51, no. 1, pp. 123-130, 2015.

[28] R. F. Li and J. J. Wang, Gear System Dynamics, Science Press, 1997.

[29] L. H. Chang, G. Liu, and J. X. Zhou, "Research on dynamic characteristics of dual-branching gear system," Journal of Ship Mechanics, vol. 17, no. 10, pp. 1176-1184, 2013.

[30] D. B. Stringer, Geared Rotor Dynamic Methodologies for Advancing Prognostic Modeling Capabilities in Rotary-Wing Transmission Systems, University of Virginia, 2008.

[31] T. C. Lim and R. Singh, "Vibration transmission through rolling element bearings, part i: bearing stiffness formulation," Journal of Sound and Vibration, vol. 139, no. 2, pp. 179-199, 1990.

[32] B. J. Stone, "The state of the art in the measurement of the stiffness and damping of rolling element bearings," CIRP AnnalsManufacturing Technology, vol. 31, no. 2, pp. 529-538, 1982. 


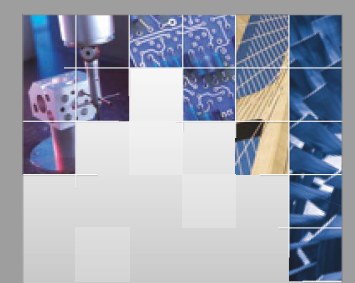

\section{Enfincering}
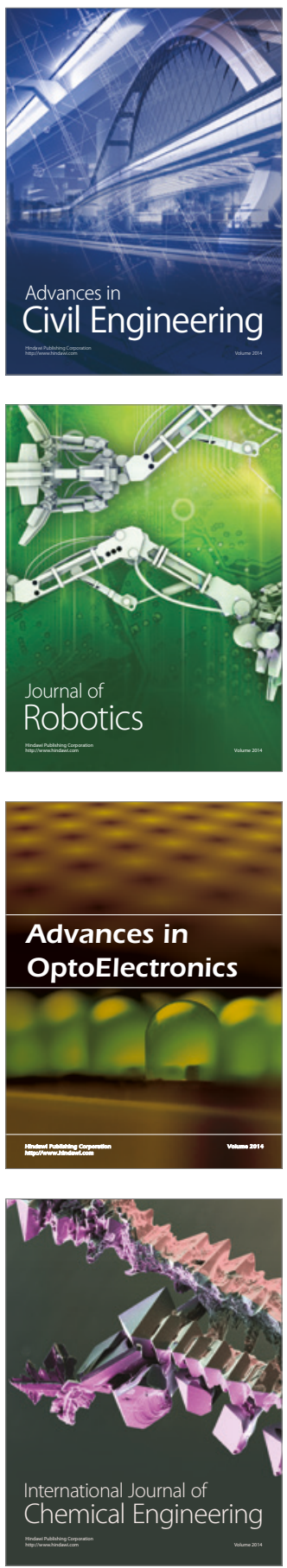

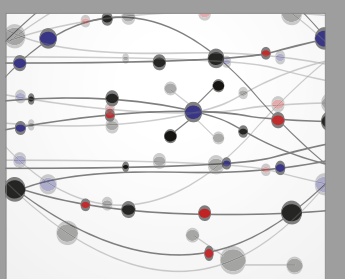

The Scientific World Journal

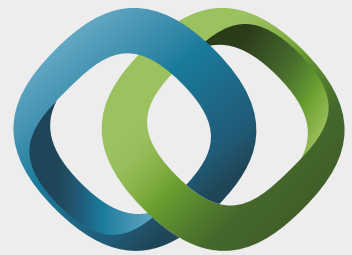

\section{Hindawi}

Submit your manuscripts at

https://www.hindawi.com
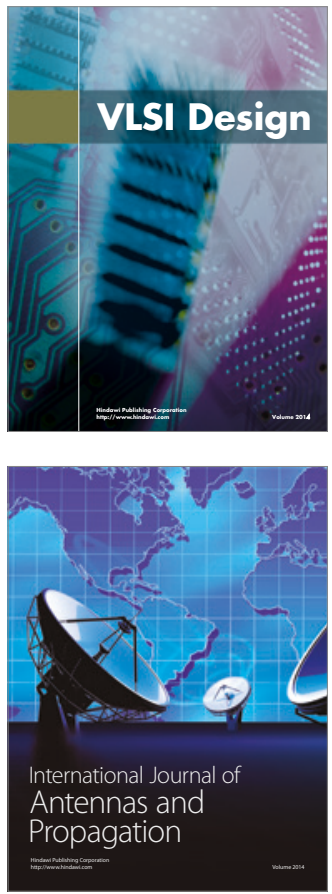

\section{Rotating}

Machinery
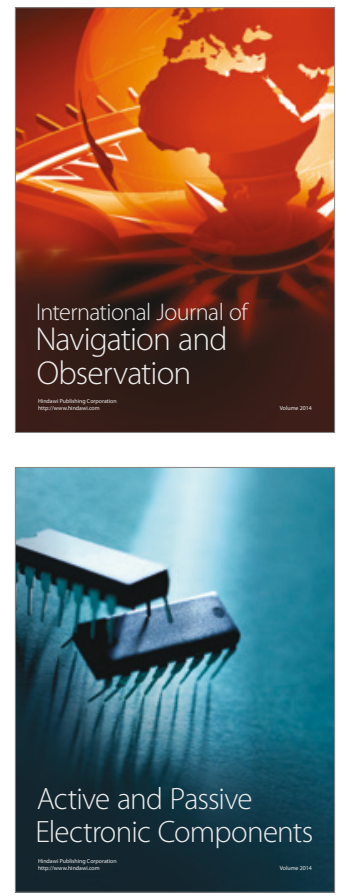
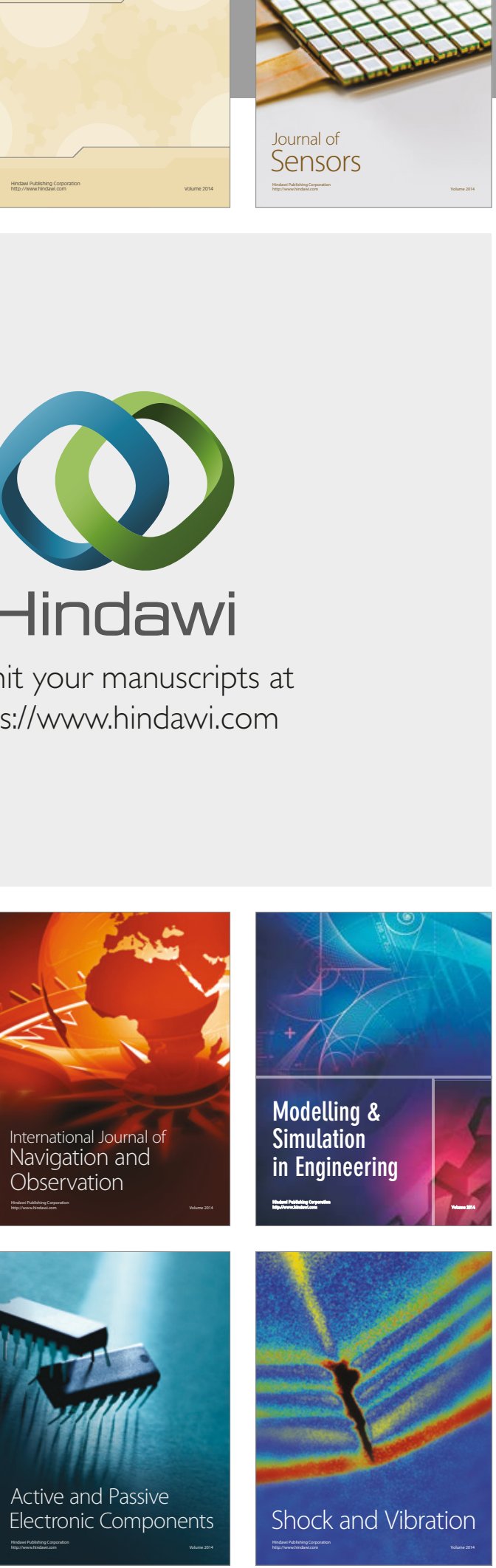
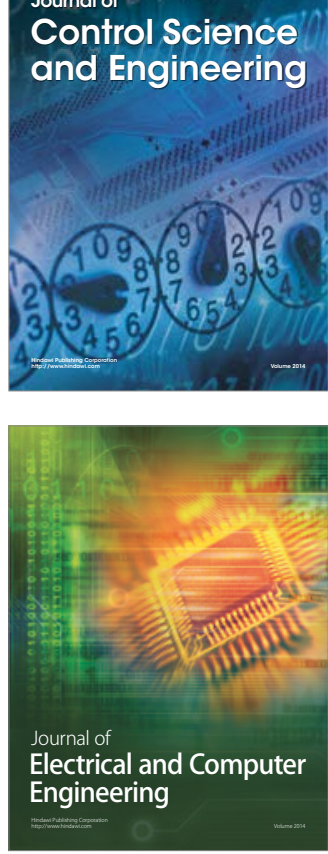

Distributed

Journal of

Control Science

and Engineering
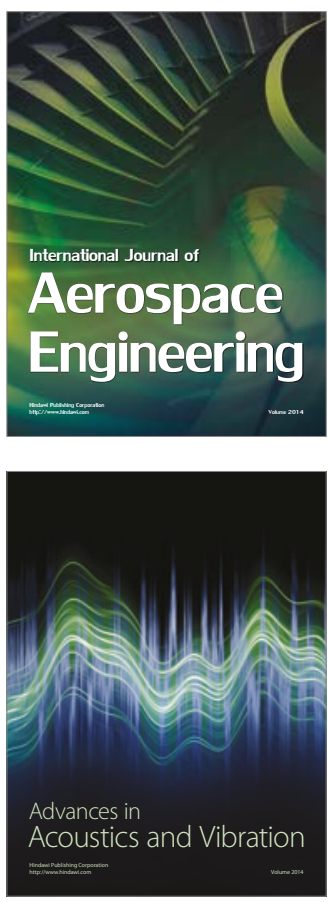

Sensor Networks 